\title{
Hemimicelles of Alkyl Carboxylates Chemisorbed onto Magnetic Nanoparticles: Study and Application to the Extraction of Carcinogenic Polycyclic Aromatic Hydrocarbons in Environmental Water Samples
}

\author{
A. Ballesteros-Gómez, S. Rubio \\ Departamento de Química Analítica \\ Universidad de Córdoba \\ Edificio Anexo Marie Curie. Campus de Rabanales. CP:14004 \\ a02bagoa@yahoo.es; http://www.uco.es/grupos/FQM-186/
}

Hemimicelles and admicelles are flexible materials with unique features for the solid phase extraction of a variety of pollutants from the environment (1-3). The multiple reaction mechanisms that may come into play make these materials excellent sorbents for multiclass pollutant extraction. Some applications, however, have been hindered because disruption of surfactant aggregates during analyte elution produces extracts containing high surfactant concentration that may suppress ionization in MS or interfere with MS,UV or fluorescence detection. On the other hand, hemimicelles/admicelles are preferentially used in the cartridge format, which results in slow extraction and low breakthrough volumes.

In this work, we assessed the ability of new surfactant-mineral oxides systems (alkyl carboxylate-magnetite) to circumvent the above-described shortcomings. Magnetic nanoparticles (MNPs) coated with hemimicelles of alkyl $\left(\mathrm{C}_{10}-\mathrm{C}_{18}\right)$ carboxylates, which have traditionally been used to prepare ferrofluids for technological applications, were used for the first time to extract organic contaminants from environmental water samples. The nanoparticles were coated by following a simple, rapid procedure (30 min at $85{ }^{\circ} \mathrm{C}$ ) that uses commercially available magnetite of 20-30 nm mean particle diameter. The strong chemical bonding between the surfactant and magnetite prevented leaching of the surfactant and permitted its reuse and the obtainment of surfactant-free extracts. Tetradecanoate hemimicelles were used to extract carcinogenic polycyclic aromatic hydrocarbons (CPAHs) prior to analysis by liquid chromatography and fluorescence detection. The procedure involved stirring of aqueous samples $(350 \mathrm{~mL})$ with $200 \mathrm{mg}$ of tetradecanoate-coated MNPs for $15 \mathrm{~min}$, isolating the sorbent with a Nd-Fe-B magnet and eluting the CPAHs with a mixture of acetonitrile and tetrahydrofuran. The limits of quantitation obtained, $0.2-0.5 \mathrm{ng} \mathrm{L}^{-1}$, met the stringent water quality requirements established by the recently amended European Water Framework Directive 2000/60/EC and also the U.S. EPA for the determination of CPAHs in surface and ground waters. The proposed method was successfully applied to the determination of these pollutants in surface and ground environmental water samples collected from various places in southern Spain. Recoveries from samples spiked with CPAHs at concentrations of $1-10 \mathrm{ng} \mathrm{L}^{-1}$ ranged from 85 to $94 \%$ and relative standard deviations from 1 to $7 \%$.CPAHs were only present in the sample from the Navallana reservoir, at concentrations over the range $0.42-0.96 \mathrm{ng} \mathrm{L}^{-1}$.

1. F. Merino, S. Rubio, D. Pérez-Bendito. Anal. Chem. 75 (2003) 6799.

2. F. Meriono, S. Rubio, D. Pérez-Bendito Anal. Chem. 76 (2004) 3878.

3. S. Rubio, D. Pérez-Bendito, Anal. Chem. 81 (2009) 4601. 